This item was submitted to Loughborough's Research Repository by the author.

Items in Figshare are protected by copyright, with all rights reserved, unless otherwise indicated.

\title{
Wideband blade monopole antenna with sleeved coaxial feed
}

PLEASE CITE THE PUBLISHED VERSION

http://dx.doi.org/10.1109/LAPC.2009.5352412

PUBLISHER

Loughborough University (@ IEEE)

VERSION

AM (Accepted Manuscript)

LICENCE

CC BY-NC-ND 4.0

REPOSITORY RECORD

Morrow, Ivor L., G.P. Dingley, W.G. Whittow, and A. Cooper. 2019. "Wideband Blade Monopole Antenna with Sleeved Coaxial Feed". figshare. https://hdl.handle.net/2134/9999. 
This item was submitted to Loughborough's Institutional Repository (https://dspace.lboro.ac.uk/) by the author and is made available under the following Creative Commons Licence conditions.

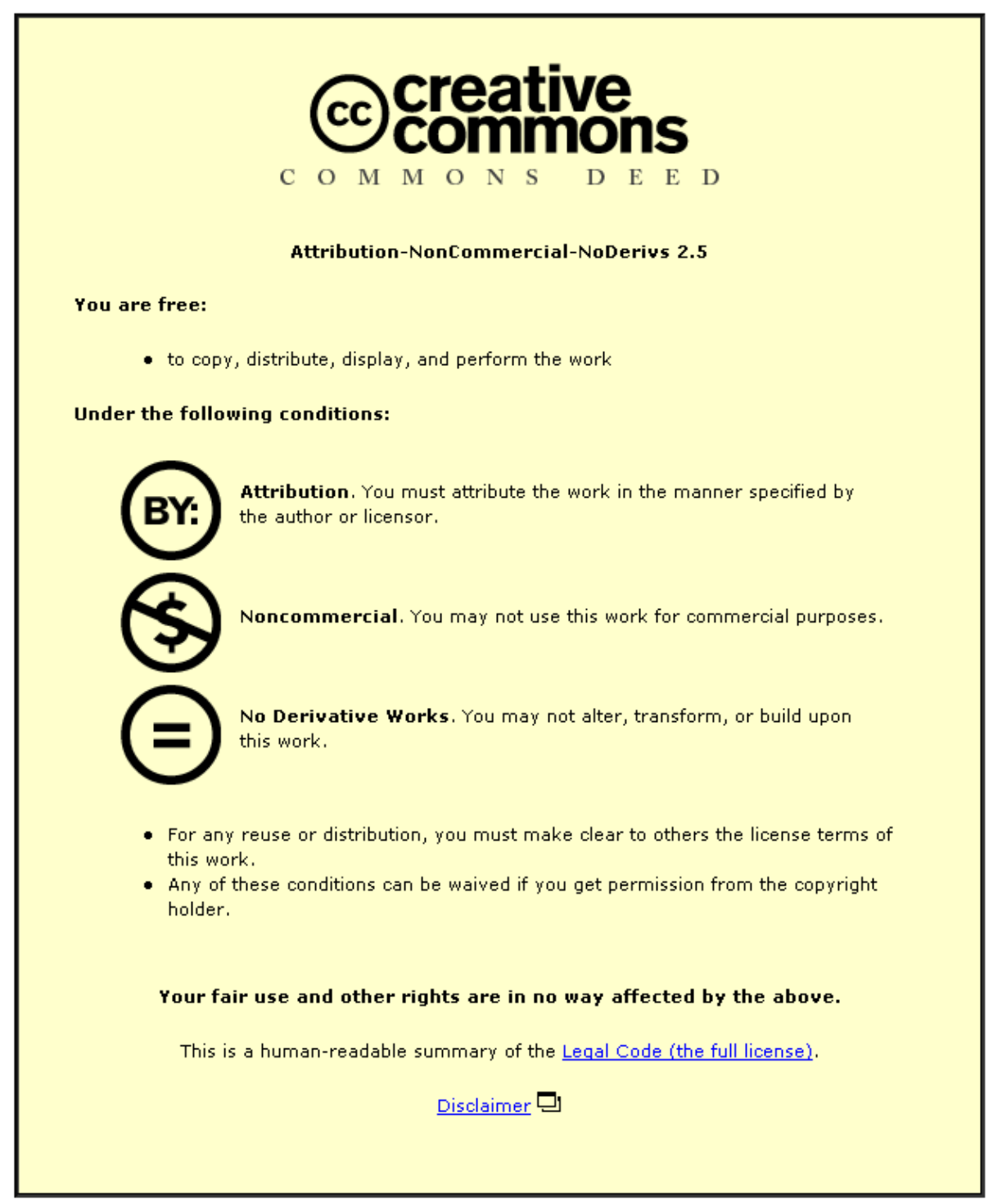

For the full text of this licence, please go to: http://creativecommons.org/licenses/by-nc-nd/2.5/ 


\title{
Wideband Blade Monopole Antenna with Sleeved Coaxial Feed
}

\author{
I. L. Morrow ${ }^{\# 1}$, G. P. Dingley ${ }^{\# 1}$, W. G. Whittow ${ }^{\# 2}$ and A. Cooper ${ }^{\# 3}$ \\ ${ }^{\# 1}$ Cranfield University, Shrivenham, Oxfordshire, SN6 8LA, UK \\ ${ }^{\# 2}$ Loughborough University, Loughborough, Leicestershire, LE11 3TU, UK \\ ${ }^{\# 3}$ Royal Navy, DSTL, Portsdown West, UK
}

\begin{abstract}
A wideband planar monopole antenna requiring a small ground plane is described. Numerical and measured results confirms the antenna has good radiation efficiency and stable omni-directional radiation patterns over an impedance bandwidth of $4.1: 1$ covering the $200-850 \mathrm{MHz}$ frequency spectrum.
\end{abstract}

\section{INTRODUCTION}

The monopole antenna is one of the most versatile antenna types used over frequencies ranging from HF to millimetre wave lengths. As is well known the impedance bandwidth of a thin monopole can be increased by modifying the wire element geometry, for example by thickening or meandering the wire element or adding material loading [1, 2]. Previous wideband monopoles that use such design techniques include the top-hat, ferrite and/or dielectric clad monopole, the discone and the caged monopole. These elements tend to be bulky and occupy a relatively large physical volume. Recently, planar monopole designs have been proposed that considerably reduce the volume of elements and have wideband impedance bandwidths [3, 4].

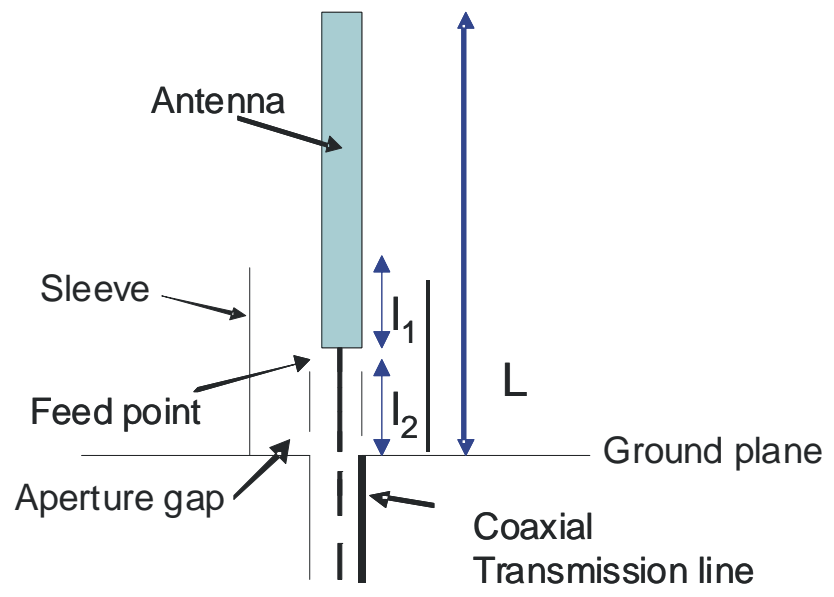

Fig. 1 Sleeved monopole antenna with elevated feed point [3].

In [5] an improved method of matching to the monopole element has been developed, and is shown in Fig. 1. Essentially the feed point of the monopole is elevated above its own enclosed ground plane and then enclosed by another outer cylindrical sleeve, so forming a coaxial line within a coaxial line. The outer coaxial line or sleeve is shorted to ground while the inner coaxial line is open circuited with an aperture near the ground. The radiating antenna that protrudes out of the enclosing sleeve is an extension of the centre conductor of the inner coaxial line. The total height of the monopole antenna is $L$ and it resonates at $L \approx \lambda / 4$, the lowest frequency. The coaxial transmission lines form a distributed two-pole tuned impedance transformer with the input impedance given as [6],

$$
Z_{i n}=Z_{01} \frac{Z_{a}+j Z_{01} \tan \beta l_{1}}{Z_{01}+j Z_{a} \tan \beta l_{2}}+j Z_{02} \tan \beta l_{2}
$$

Where $\beta=2 \pi / \lambda$ is the free space phase constant, $Z_{01}, Z_{02}$ are the impedances of the coaxial transmission lines of length $l_{1}$ and $\mathrm{l}_{2}$ respectively, and $\mathrm{Z}_{\mathrm{a}}$ is the input impedance of the isolated monopole. Using this technique it is feasible to provide a match to a thin monopole over a $4: 1$ frequency range [10]. This paper reports a new form monopole antenna composed of the sleeved coaxial feed attached to a planar monopole. The antenna is capable of wideband operation with improved impedance and pattern bandwidth and requires little, or no, external ground plane.

\section{ANTENNA DESIGN}

The antennas design is broken down into two stages. Section A deals with the antenna design and characterisation in isolation. Section B examines integration of the antenna with the elevated coaxial feed and sleeve sections. The antennas impedance match and radiation patterns are examined on a range of different sized ground planes.

\section{A. Blade Antenna}

Planar broadband monopole design is based on the use of a number of primitive geometric shapes used either alone or in combination. Likely shapes included the bicone or bow-tie [7], square or rectangle [8], circle [3] and volcano or inverted cone shape [9]. The design principle is the same in all cases, for a 
Final author version. 2009 Loughborough Antennas \& Propagation Conference (LAPC), Loughborough, UK, pp 789-792, 1617 Nov. 2009

fixed height to width each of these shapes can be scaled to provide the same bandwidth. Bandwidths of 5:1 up to 10:1 are feasible with a radiation pattern that is omni-directional in azimuth and single lobed in elevation. However, at higher frequency the radiation pattern shows perturbation since at these shorter wavelengths the antenna becomes electrically large. In this paper we use a novel tapered planar monopole geometry that resembles a "blade" shape. The blade is a combination of tapered rectangle and elliptical shapes, where the larger ellipse has been optimised to provide a wideband impedance transition with minimum mismatch. Fig. 2 shows a picture of the geometry and dimensions of the constructed blade monopole.

Fig. 3 shows the Ansoft HFSS simulated return loss for the blade antenna as a function of height above an infinite ground plane. It can be observed that the effect of increasing height is to enhance the impedance match. The optimum height was found from both simulation and measurement to be $13-15 \mathrm{~mm}$. Fig. 4 shows a comparison of the measured and simulated $S_{11}$ for the antenna over a smaller frequency range. The antenna was measured on an $80 \times 80 \mathrm{~cm}$ square ground plane. The operating bandwidth of many antennas is typically defined as a VSWR of 2.0:1 with respect to $50 \Omega$ characteristics impedance, and on that basis the blade monopole bandwidth ranges from $400 \mathrm{MHz}$

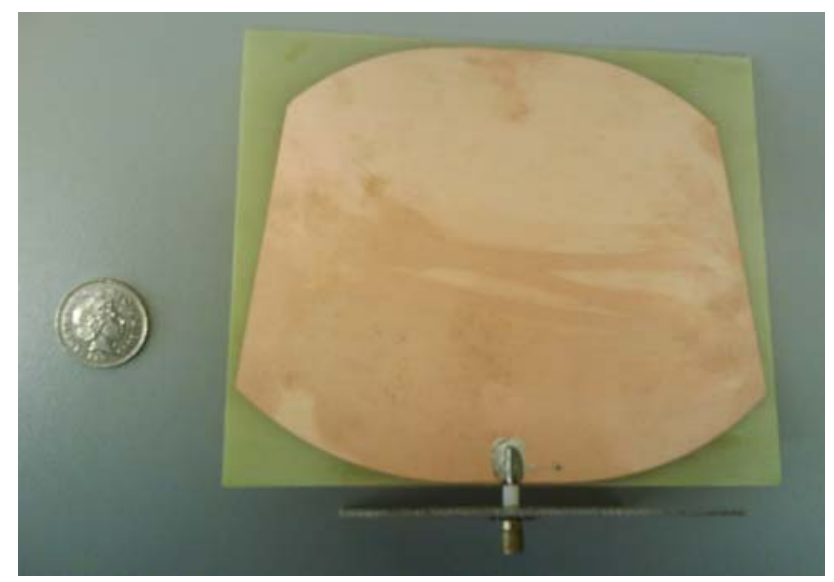

Fig. 2 Picture of the wideband blade monopole antenna (Dimensions: height $=145 \mathrm{~mm}$, width $=166 \mathrm{~mm}$, bevel angle $15^{\circ}$ ).

to a frequency in excess of $6.0 \mathrm{GHz}$ (12:1 bandwidth). Note that the IEEE 802.11 standard sets more stringent impedance matched conditions and specifies the antenna VSWR to be less than 1.5:1. At the lower end of the operating band the antenna has a height of $0.20 \lambda$. The addition of the sleeved feed increases the total antenna height to $\approx 0.26 \lambda$.

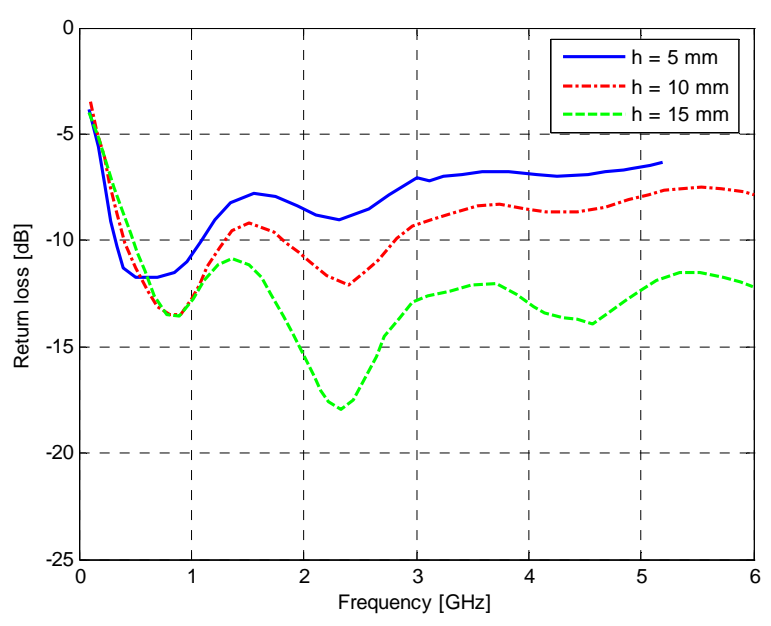

Fig. 3 Simulated and measured return loss for the blade monopole antenna as a function of height above the ground plane.

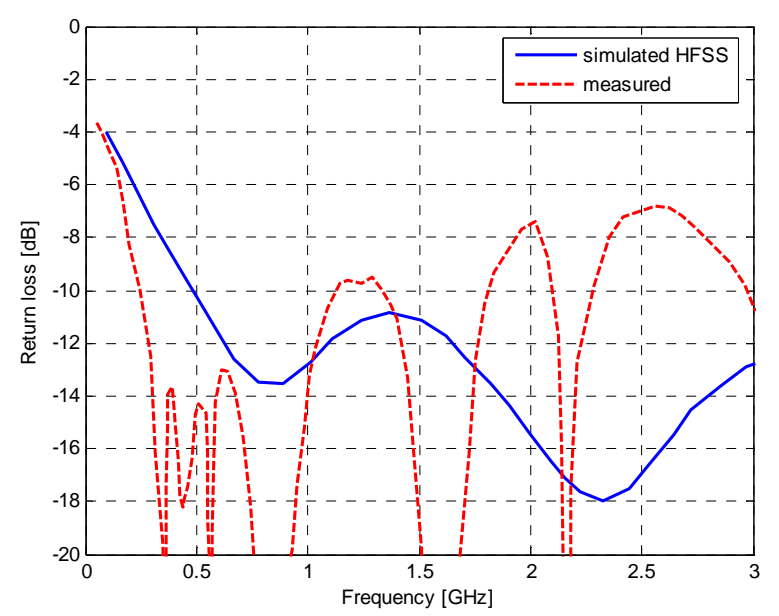

Fig. 4 Simulated and measured return loss for the blade monopole antenna on an $80 \times 80 \mathrm{~cm}$ square ground plane.

\section{B. Sleeved Coaxial Fed Blade Monopole}

The antenna is attached to the sleeved and elevated coaxial feed section as shown in Fig. 1. The antenna protrudes $15 \mathrm{~mm}$ above the larger outer cylindrical metallic sleeve. A coaxial line impedance transformer of length $l_{1}$ composed of the outer conductor of the surrounded coaxial antenna feed line and the inner conductor of the cylindrical sleeve forms a short $(\lambda / 12)$ transformer of impedance $\mathrm{Z}_{01} \approx 105 \Omega$.

A coaxial line of length $l_{2}$ is formed from the inner conductor of the feed coaxial line and the sleeve making a transmission line of characteristic impedance $\mathrm{Z}_{02} \approx 22 \Omega$. A small annular aperture is cut on the outer conductor of the surrounded coaxial transmission line section, where the cable enters the 
Final author version. 2009 Loughborough Antennas \& Propagation Conference (LAPC), Loughborough, UK, pp 789-792, 1617 Nov. 2009

ground plane so that the $\mathrm{Z}_{02}$ impedance forms a short circuited line. The height of the aperture was $1.5 \mathrm{~mm}$ and it primarily controls the bandwidth of the impedance match; the aperture height was optimised using Ansoft HFSS.

The assembled antenna is shown in Fig. 5. As discussed earlier the matched bandwidth of the sleeve design is much less than the impedance bandwidth of the blade monopole. Here we are interested in the overlap of the useable radiation pattern bandwidth combined the bandwidth over which the sleeve mitigates the use of a ground plane.

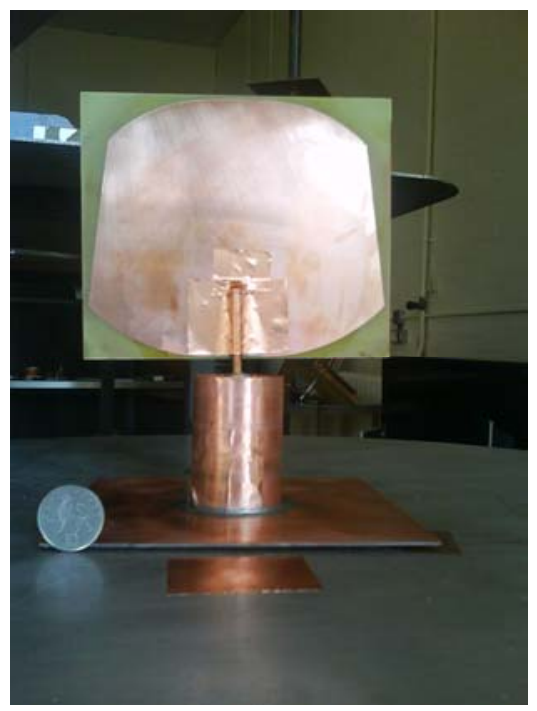

Fig. 5 Picture of the wideband blade monopole antenna with sleeved coaxial feed (dimensions: inner pin diameter $=5 \mathrm{~mm}$, inner coax diameter $=20 \mathrm{~mm}$, sleeve diameter $=30 \mathrm{~mm}$, sleeve height $=50 \mathrm{~mm}$ ).

The impedance and radiation properties of the antenna have been examined by measurements and numerical experiments using HFSS. Fig. 6 shows the measured and analytically calculated, using Eq. 1, return loss for the antenna on a truncated ground plane of $5 \times 5 \mathrm{~cm}$ sq. The measured return loss for the antenna on ground planes of larger sizes are also shown in Fig. 7. The effect of increasing the ground plane size on the antennas impedance matched bandwidth is minimal. Increasing the ground plane size acts to suppress resonances in the return loss. The VSWR is nearly less that $1.5: 1$ over a 4:1 bandwidth. This suggests that the sleeve feed is screening the antenna properties from its external environment. The accompanying poster will illustrate that the field structure over the external conducting sleeve remain almost frequency invariant over the desired antenna operating bandwidth.

\section{RADIATION PATTERNS}

The radiation patterns for the antenna were simulated in both the principal $\mathrm{H}$ and $\mathrm{E}$ planes and are shown in Figs. 8 and 9 , respectively. The radiated fields are consistent with physical intuition having an omni-directional pattern in the horizontal plane and a single null in the elevation plane. Fig. 10 shows the measured radiation patterns for the antenna in the horizontal plane at $500 \mathrm{MHz}$ on different sizes of ground plane. The fields were measured at an outdoor range and calibrated using a standard dipole. The measured field patterns are consistent with simulations although there is a slight perturbation at one angle. This anomaly was due to the setup of the outdoor measurement environment. The radiated fields where measured across the entire operating band 220-900 $\mathrm{MHz}$ and the patterns where found to maintain stable omnidirectional performance. This is in contrast to other reported planar wideband monopoles feed on large ground planes were pattern instability (and impedance mismatch) become apparent with increasing frequency. The realised antenna gain which includes losses was also measured and simulated for a number of frequencies and is given in Table 1.

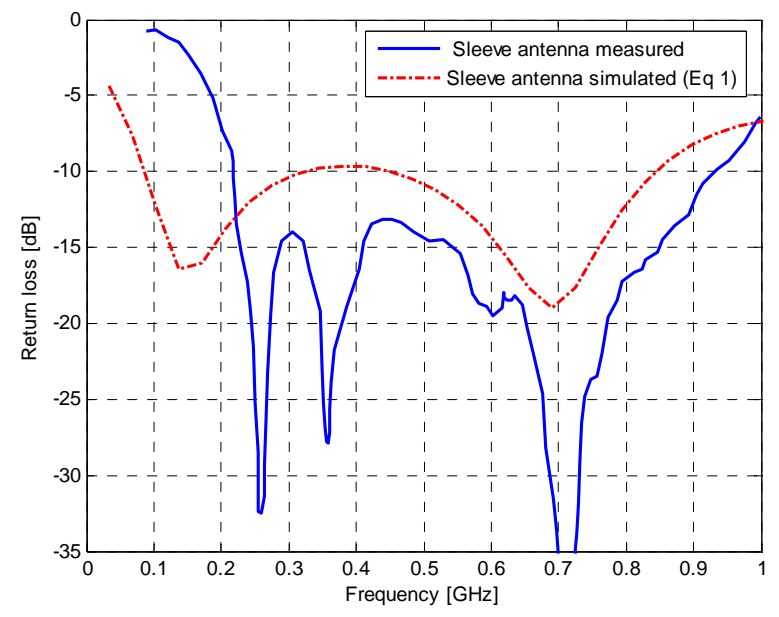

Fig. 6 Measured and simulated return loss for the antenna on a finite sized ground plane of $50 \times 50 \mathrm{~mm}$.

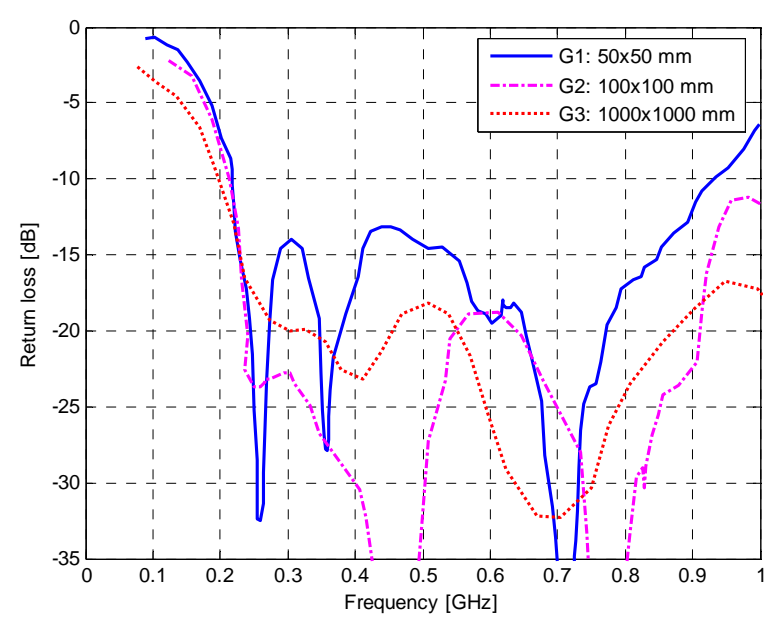


Final author version. 2009 Loughborough Antennas \& Propagation Conference (LAPC), Loughborough, UK, pp 789-792, 16-

17 Nov. 2009

Fig. 7 The measured return loss for the antenna on ground planes G1, G2 and G3 of increasing size.

TABLE 1 ReALISEd Gain OF SLEEVEd BLADE MONOPOLE

\begin{tabular}{|l|c|c|}
\hline Frequency $[\mathrm{MHz}]$ & \multicolumn{2}{|c|}{ Realised gain $[\mathrm{dBi}]$} \\
\hline & Measured $( \pm 1 \mathrm{dBi})$ & Simulated \\
\hline 250 & 3.0 & 2.0 \\
\hline 500 & 3.5 & 3.5 \\
\hline 750 & 5.0 & 4.7 \\
\hline
\end{tabular}

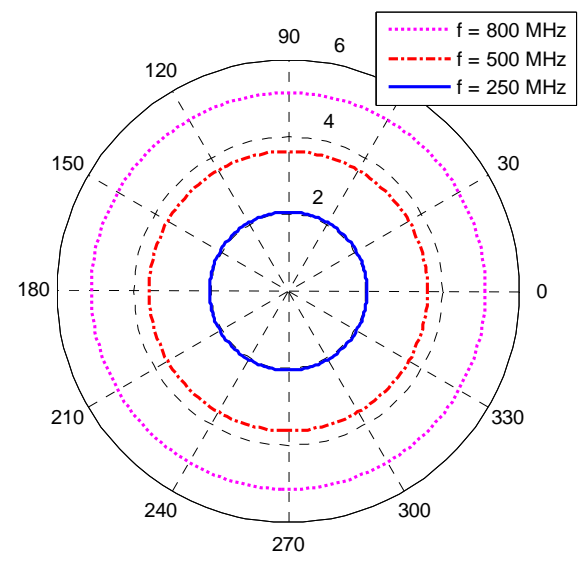

Fig. 8 Radiation patterns simulated for the antenna in the $E_{\theta}$ component of the $\mathrm{H}$-plane ( $2 \mathrm{dBi} / \mathrm{div})$.

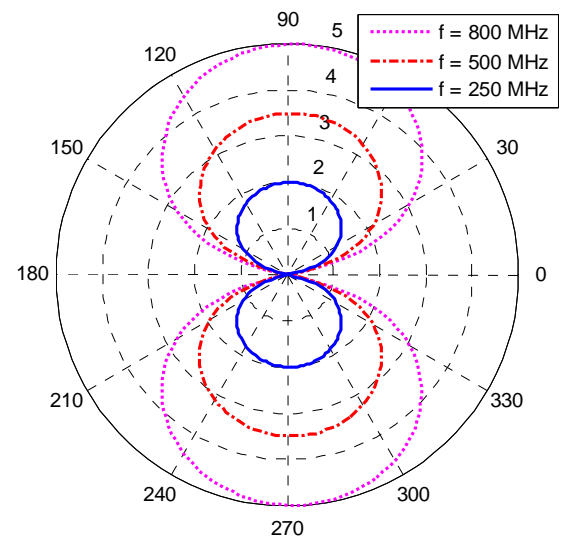

Fig. 9 Radiation patterns simulated for the antenna in the $E_{\theta}$ component of the E-plane (1 dBi/div).

\section{CONCLUSIONS}

A wideband planar monopole antenna is presented combining a planar blade and novel sleeved coaxial feed transmission line. The antenna was simulated and measured with reasonable agreement. The sleeved feed enables the antenna to operate on very limited size ground planes. The antenna has a wideband 4:1 impedance matched bandwidth with omni-directional pattern in the azimuth plane and is dipole like in elevation. The antenna is intended for easy installation on a variety of platforms where minimum perturbations to impedance and radiation pattern performance are the foremost requirements.

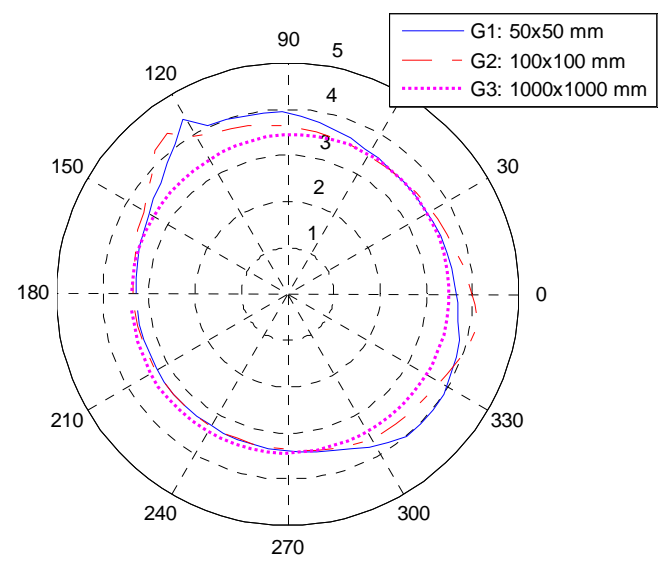

Fig. 10 Measured radiation pattern of the antenna $E_{\theta}$ component of the H-plane at $500 \mathrm{MHz}$ with different ground plane sizes G1, G2 and G3 (1 dBi/div).

\section{ACKNOWLEDGMENT}

The authors are grateful to Miss Stacy Paget from the Electrical Workshops for the construction and milling of the PCB blade antenna and coaxial sections.

\section{REFERENCES}

[1] H. Jasik, Editor, “The Antenna Engineering Handbook” Chapter 3, First Edition, McGraw-Hill Book company, Inc 1961, CCN 59-14455.

[2] S. R. Best, "Small broadband disk loaded folded monopole antennas", Antennas Application Symposium, Allerton, 2008.

[3] J. Liang, C. Chiau, X. Chen and C. Parini, "Study of a printed circular disc monopole antenna for UWB Systems”, IEEE Trans. Antennas and Propagat. , 53, 11, 3500-3504, 2005.

[4] K. Thomas and M. Sreenivasan, "A simple dual band microstrip fed printed antenna for WLAN applications”, IET Microw. Antennas and Propagat., vol. 3, issue 4, pp. 687-694, 2009.

[5] A. J. Poggio and P. E. Mayes "Pattern bandwidth optimization of the sleeve monopole antenna”, IEEE Trans. Antennas and Propagat. Vol. AP-14, No. 5, pp. 643-645, Sept. 1966.

[6] D. M. Pozar, "Microwave engineering”, J. Wiley and Sons Ltd, ISBN 9480471448785, 2004.

[7] C. A. Balanis, “Antenna Theory: Analysis and Design”, J. Wiley and Sons Ltd, ISBN 0-471-66782-X, 2005.

[8] M. J. Amman and Z. N. Chen, "Wideband monopole antennas for multi-band Wireless Systems”, IEEE Ants and Propagat Mag., vol. 45, No. 2, pp. 146-150, April, 2003.

[9] S. Y. Suh, W. L. Stutzman and W. A. Davis, "A new ultrawideband printed monopole antenna: the planar inverted cone antenna (PICA)”, IEEE Trans. On Ants and Propagat. Vol. 52, No. 5, pp. 1361-1365, May, 2004.

[10] K. Thomas, N. Lenin and M. Sreenivasan, "Wideband dual sleeve antenna”, IEEE Trans. On Ants and Propagat., vol. 54, No. 3, March, pp. 1034- 1037, 2006. 